\title{
THE GOOD, THE BAD AND THE UGLY - THE SAGA OF MALARIA CONTROL IN HUMANITARIAN EMERGENCIES
}

\author{
Mark Rowland, Editorial Board Member and Louisa A. Messenger, London School of Hygiene and Tropical \\ Medicine, UK
}

\begin{abstract}
Natural disasters and humanitarian emergencies arising from war and conflict present special problems for malaria control. Entire populations may be uprooted and forced to flee from stricken villages and towns. Homes may be destroyed leaving families no choice but to take refuge in displacement camps far removed from their homeland. Having no alternative but to live outdoors under makeshift shelter increases the risk of being exposed to malarial mosquitoes. Combined with the stress of dislocation, an uncertain future, possible malnourishment and loss of immunity, refugee populations may be subject to epidemics of malaria and suffer high rates of mortality. Examples of recurrent malaria epidemics in conditions of protracted conflict include southern Sudan and Afghanistan to name but two (WHO 2013a).
\end{abstract}

By contrast, in countries at peace, malaria control programmes faced with a rising malaria outbreak can turn to two stalwarts of malaria vector control: a campaign of indoor spraying with residual insecticide (e.g. pyrethroid or organophosphate) or insecticide treated nets distributed to populations at risk. In countries at war, displaced populations may not have the luxury of inhabiting intact housing or even basic dwellings which can be sprayed, and what shelter there is might not be suitable for hanging long-lasting insecticidal nets. Faced with these nigh impossible conditions, agencies specializing in health care in emergencies may simply focus on treating cases of malarial disease as they occur rather than tackle the seemingly impossible challenge of what might be done, if anything, to prevent the disease or control the mosquito vector.

Agencies specialising in general health may also not have the in-house expertise to identify solutions. One Afghan refugee group which would migrate seasonally in search of work
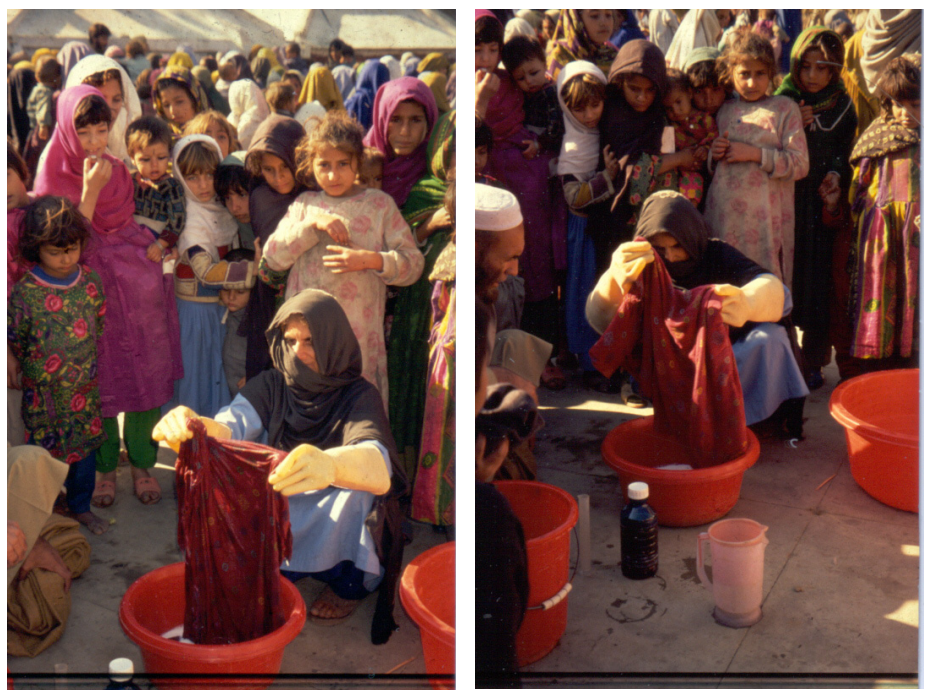

Figure I. Dipping chadors in permethrin. proved difficult to track and would suffer high rates of malaria. Only when external experts came up with the novel idea of spraying with pyrethroid the internal surfaces of their tents, which they carried on their camel caravans from Waziristan to Punjab was the problem finally solved (Bouma et al. 1996). This led to the concept of locally appropriate technology or socially acceptable solutions. The chador wrap that features so prominently in the everyday lives of Muslim women and which doubles at night as a makeshift blanket to keep themselves and their children warm offered another potential solution for protection against malaria. Treatment of chadors, sheets and blankets with the repellent pyrethroid permethrin was enough to prevent new cases of malaria in Afghan refugee populations (Rowland et al. 1999). In bombed out Kabul, before the Allied occupation post 9/11, the resident population suffered epidemics of leishmaniasis, transmitted by sandflies which thrived among the rubble created by the warring factions. Treatment of blankets with permethrin helped solve the problem (Reyburn et al. 2000). Refugees from the Syrian city of Aleppo, destroyed by war and historically endemic for leishmaniasis are now suffering epidemics of the disease (Al-Salem et al. 2016).

If refugee agencies have their attention on bigger issues than local vector borne diseases, the appropriate solution is to make their standard response kit for refugees fit for preventing malaria and leishmaniasis without recourse to specialist expertise or additional intervention. Blankets, tents, and plastic tarpaulins are routinely distributed as the first humanitarian response to emergencies and disasters. Stockpiles should be pre-treated with repellent insecticide to deal with any possibility of vector borne disease should there be any risk. Modern technology can provide this. All long-lasting insecticidal nets (LLIN), the primary tool for preventing malaria are pre-treated with pyrethroid formulations which can withstand multiple washes. Blankets are routinely pre-treated with microencapsulated permethrin for the American fishing and hunting fraternity and for leisure use where biting flies are a nuisance. Plastic tarpaulins, made from laminated polyethylene, can be impregnated with pyrethroid and formulated for slow release to the surface where it can contact mosquitoes and flies. Deltamethrin treated plastic tarpaulins (DTPT) are already developed for shelter and vector control purposes in refugee camps. A trial of DTPT in refugee camps in Sierra Leone successfully prevented malaria while neighbouring refugee groups issued with untreated tarpaulins suffered three times as much disease transmission (Burns et al. 2012).

These ideas are no longer new. Insecticide treated blankets and tarpaulins were conceived of 15-20 years ago. However, the route to market for novel insecticidal products for public health is not straightforward. Such products first require 


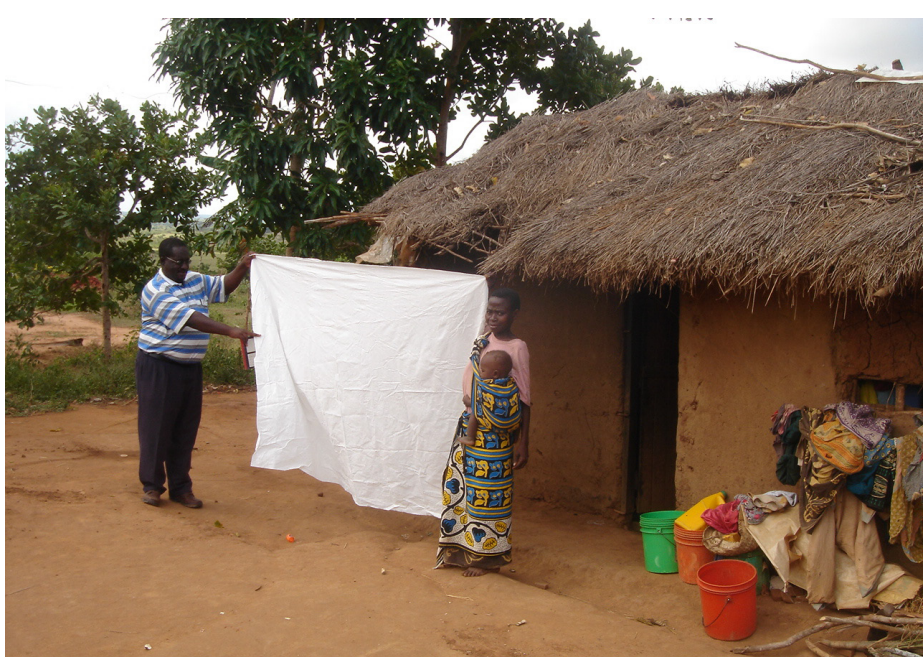

Figure 2. Factory produced, permethrin treated blankets.

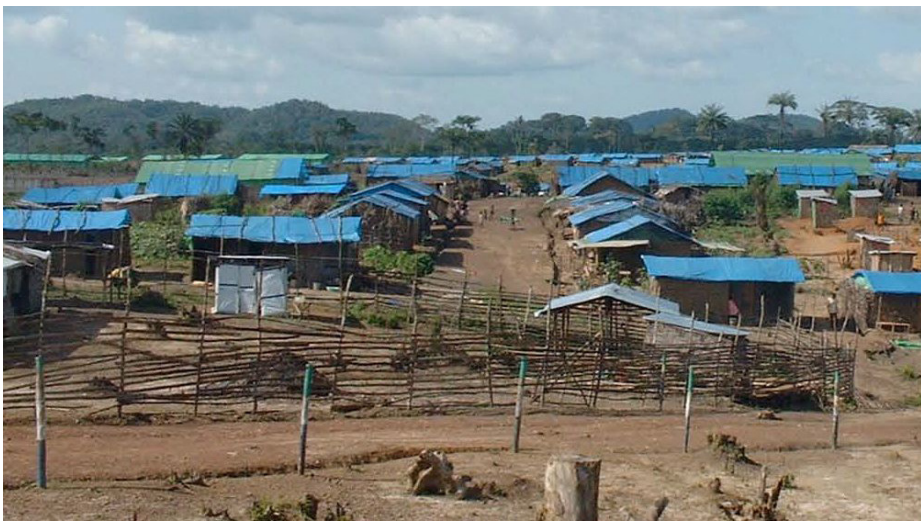

Figure 4. Sierra Leone refugee camp of insecticide treated plastic tarpaulins.

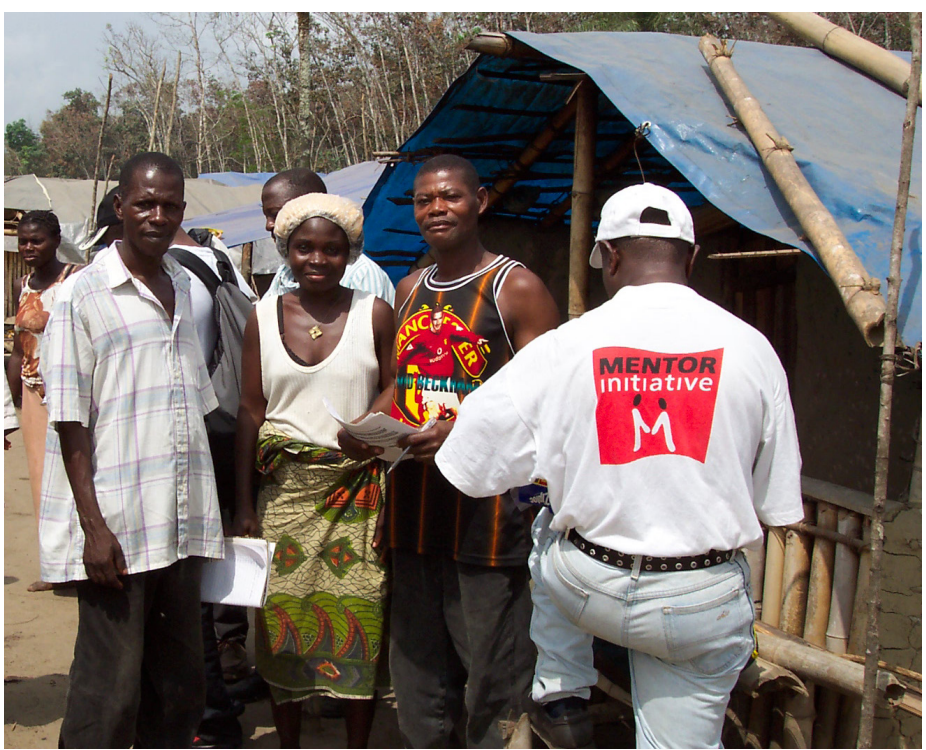

Figure 5. Sierra Leone refugees and structures made from insecticide treated plastic tarpaulins.

proof of effectiveness and recommendation from the World Health Organisation (WHO) before national malaria control programmes would consider using them. By contrast, the route to market for more standard methods, like long-lasting insecticidal nets or indoor residual insecticide spray products (IRS), is more established. Guidelines on how LLIN and IRS products

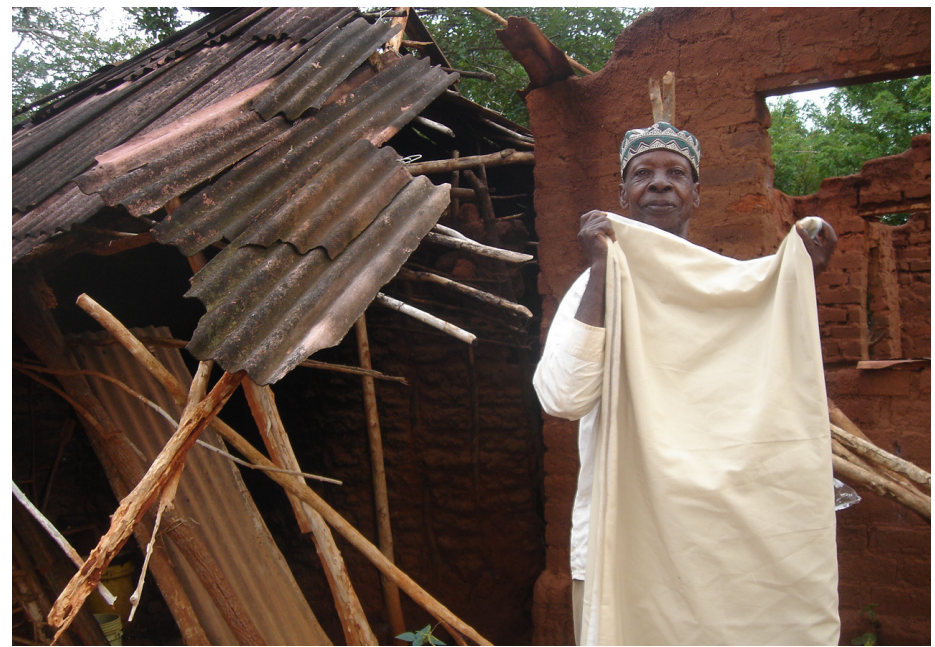

Figure 3. Factory produced, permethrin treated blankets.

should be tested and approved are kept up to date by WHO (WHO 2013b). The market for LLIN and IRS products is large enough for companies to invest in $\mathrm{R} \& \mathrm{D}$ and $\mathrm{WHO}$ evaluation. If LLIN and IRS products are good enough or cheap enough they will be bought by the Global Fund and other multilateral agencies. For niche products like blankets, tents or tarpaulins, WHO guidelines on testing and evaluation do not exist and even if they did exist would manufacturers be prepared to take the risk of investing in development and evaluation? One or two brave companies have taken the plunge, and for a while deltamethrin treated plastic tarpaulins were being distributed in emergencies. But if humanitarian emergency was not a bad enough problem to deal with, there is now the ugly threat of pyrethroid resistance lurking in the shadows and spreading across Africa to make the problem of malaria even worse and threaten these innovative control solutions. Pyrethroids are no longer recommended for IRS where there is risk of further selecting for resistance because, it is argued, LLINs should be protected as a priority as no class of insecticide other than pyrethroids is suitable for LLIN. One of the fall-outs from this is that pyrethroid treated tarpaulins - as a type of long lasting IRS - are no longing being manufactured.

While this has been happening the idea of developing a long lasting IRS product for peacetime use has been gathering pace. The spin off from pyrethroid treated tarpaulins for emergencies was the development of pyrethroid treated durable wall lining which will be described in a 2017 issue of Outlooks on Pest Management. The idea was that because annual IRS campaigns are a major recurrent expense for malaria control programmes, if this could be reduced to a one-time installation every 3-5 years of an insecticide-impregnated durable wall lining product this would provide a more sustainable solution than IRS in the same way that long lasting insecticidal nets replaced homedipped insecticide treated nets as more efficient way of providing protection. With the withdrawal of pyrethroid for IRS, the development of insecticide treated durable wall lining has also suffered a temporary setback. However, the potential market for durable wall lining is probably large enough to justify R\&D into non-pyrethroid alternative insecticides for wall lining. If that proves true, we can hope there will be a spin off for emergencies and new types of insecticide treated plastic tarpaulins 


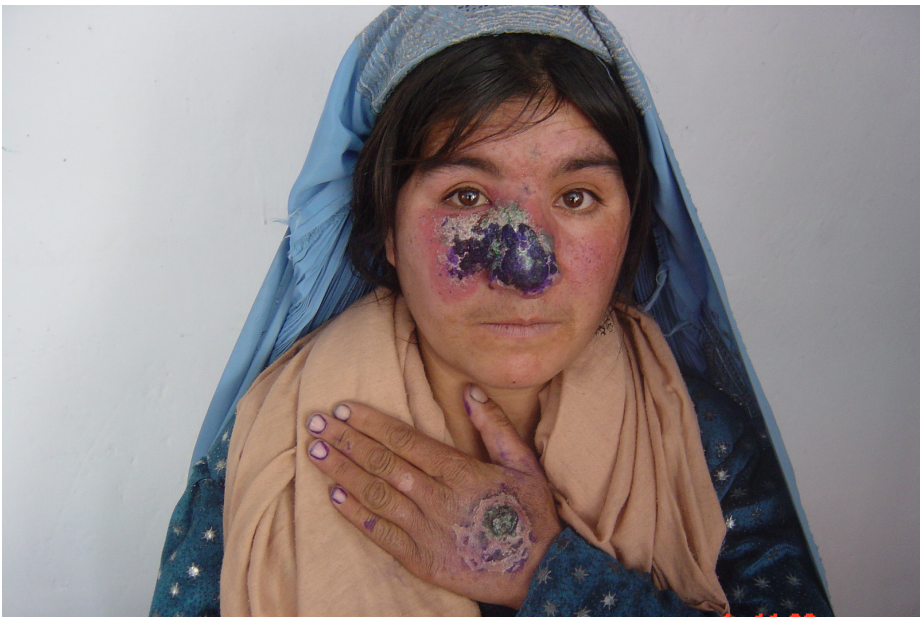

Figure 6. Leishmaniasis in Kabul.

and tents will be developed that can benefit victims of conflict and disaster in the future.

The development of long lasting repellent blankets for emergencies has been no less fraught. A long lasting permethrin treated blanket developed for the American leisure market has been adapted for refugee use. Use of the blanket disrupts permethrin microcapsules, releasing the insecticide, which repels and kills mosquitoes landing on the surface. The route to market for repellent treated blankets has been made easier by the formation by WHO of the Vector Control Advisory Group (VCAG) (WH0 2014). This committee has only been in existence a few years and prior to formation there was no clear pathway for innovative vector control products to secure recommendation from WHO. The route to market is still not easy. International malaria control authorities expect evidence, evidence requires trials, trials require money, when the return on investment for manufacturers of niche products is uncertain and the market for such products in emergencies is unpredictable. Few companies are prepared to take the risk. Published individual randomised trials of permethrin treated blankets have already demonstrated protection against malaria and leishmaniasis (Rowland et al. 1999, Reyburn et al. 2000, Macintyre et al. 2003). VCAG is calling for more randomized trials with epidemiological outcome measurements (WHO 2014). No funding body has come forward to support further trials. In the face of pyrethroid resistant mosquitoes (Anopheles and also Aedes for those concerned about the spread of Zika virus) the repellency of pyrethroids may be reduced suggests VCAG. Yes, possibly, in some places with high resistance, but pyrethroid treated LLIN are still effective according to recent multicentre trials in countries with resistance (WHO 2016) and nobody is recommending halting the use of permethrin treated LLINs. An experimental hut trial of the long lasting permethrin blanket in an area of moderate pyrethroid resistance showed continued protection (Kitau et al. 2014). It is said the good die young. In the example of tools for emergencies, the trade-off between investment required, market size and return on risk is a barrier to further progress and the present tools may die before they are given a chance to work, or be rolled out, and when there are no alternative solutions. Always there are new possibilities. One might be to combine permethrin with the synergist PBO (piperonyl butoxide) as is being considered for LLINs to control pyrethroid resistant vectors (WHO 2015). A pilot study of home- made permethrin-PBO blankets is being considered for refugees presently living in camps in northwest Tanzania. However, a new commercial product is years away and the prospect of new possibilities should never be a justification for holding back of proven interventions, in this case, of permethrin treated blankets which already have a significant evidence base. Dreams of the perfect are sometimes the enemy of the good. For some especially vulnerable groups in emergencies, the bar may need to be lowered if we are to provide any hope.

\section{References}

Al-Salem W, Pigott DM, Subramaniam K, Haines LR, Kelly-Hope L, Molyneux DH, et al. Cutaneous leishmaniasis and conflict in Syria. Emerg Infect Dis. 2016 May. http://dx.doi.org/10.3201/ eid2205.160042.

Bouma MJ, Parvez SD, Nesbit R, Winkler AM. (1996) Malaria control using permethrin applied to tents of nomadic Afghan refugees in northern Pakistan. Bull World Health Organ. 74:413-21.

Burns M, Rowland M, N'Guessan R, Carneiro I, Beeche A, Ruiz SS, Kamara S, Takken W, Carnevale P, Allan R. (2012). Insecticide treated plastic sheeting for emergency malaria prevention and shelter amongst displaced population: an observational cohort study in a refugee setting in Sierra Leone. American Journal of Tropical Medicine \& Hygiene 87:242-250.

Kitau J, Oxborough R, Kaye A, Chen-Hussey V, Isaacs E, Matowo J, Kaur H, Magesa SM, Mosha F, Rowland M, Logan J. (2014). Laboratory and experimental hut evaluation of a long-lasting insecticide treated blanket for protection against mosquitoes. Parasites \& Vectors. 7:129.

Macintyre K, Sosler S, Letipila F, Lochigan M, Hassig S, Omar SA et al. (2003). A new tool for malaria prevention: Results of a trial of permethrin-impregnated bedsheets (shukas) in an area of unstable transmission. Int J Epidemiol. 32:157-60.

Rowland M, Durrani N, Hewitt S, Mohammed N, Bouma M, Carneiro I, Rozendaal J, Schapira A. (1999). Permethrin treated chaddars and top-sheets: appropriate technology for protection against malaria in Afghanistan and other complex emergencies. Transactions of the Royal Society of Tropical Medicine \& Hygiene 93:465-472.

Reyburn H, Ashford R, Mohsen M, Hewitt S, Rowland M. (2000). A randomized controlled trial of insecticide treated bednets and chaddars or top-sheets, and residual spraying or interior rooms for the prevention of cutaneous leishmaniasis in Kabul, Afghanistan. Transactions of the Royal Society of Tropical Medicine \& Hygiene 94:361-366.

WHO $\overline{(2013 a) . ~ M a l a r i a ~ P r e v e n t i o n, ~ i n ~ ' M a l a r i a ~ c o n t r o l ~ i n ~ h u m a n i-~}$ tarian emergencies: an interagency field handbook, 2nd Edition " Howard, N; Clements-Hunt, WHO (Geneva, Switzerland).

WHO (2013b). Guidelines for laboratory and field-testing of longlasting insecticidal nets. WHO/HTM/NTD/WHOPES/2013.3. WHO, Geneva, Switzerland.

WHO (2014). Insecticide-treated materials for specific risk groups. Third meeting of the Vector Control Advisory Group; Geneva, Switzerland 12-14 November 2014. WHO/HTM/NTD/ VEM/2015.1. Geneva, Switzerland: WHO.

WHO (2015). Conditions for use of long-lasting insecticidal nets treated with a pyrethroid and piperonyl butoxide. 21-23 September 2015, WHO Evidence Review Group Meeting report and Recommendations, December 2015.

WHO (2016). Results of the Impact of Insecticide Resistance Project. Malaria Policy Advisory Committee meeting report, September 2016. Global Malaria Programme. WHO Geneva. WHO/HTM/ GMP/MPAC/2016.14. 